\title{
К ВОПРОСУ О СОСТАВЛЯЮЩИХ УСТОЙЧИВОГО РАЗВИТИЯ ПРЕДПРИНИМАТЕЛЬСКИХ СТРУКТУР
}

\author{
(c) 2021 Арошидзе Алёна Амирановна \\ кандидат экономических наук \\ Сибирский государственный университет путей сообщения, Россия, Новосибирск \\ E-mail: aroshidzealyona@gmail.com
}

Рассмотрены ключевые подходы к структурной характеристике устойчивого развития предприятий. Представлены результаты компонентного анализа, в рамках которых составляющие сгруппированы по частоте выделения в разрезе предприятий различных размеров и сфер деятельности. Обоснована авторская точка зрения на компоненты устойчивого развития, преобразующая традиционную триаду в тетраду.

Ключевые слова: устойчивое развитие, составляющие, компонентный анализ, триада, тетрада

Основываясь на теоретических воззрениях отечественных и зарубежных авторов на сущность устойчивого развития предприятий, можно сделать вывод, что существует три его основные составляющие компоненты, т.е. виды устойчивости - экономическая, социальная, экологическая. При этом, как правило экономическая составляющая имеет дальнейшее подразделение на подвиды устойчивости (рыночная, маркетинговая, инвестиционная и пр.) [2]. В некоторых случаях такого подразделения не наблюдается, и в качестве составляющих устойчивого развития выделен целый ряд видов устойчивости, которые по своей смысловой нагрузке в той или иной степени относятся к экономической, социальной, экологической компоненте. Помимо целесообразности такого распределения видов устойчивости в рамках общей системы компонентов устойчивого развития или дальнейшей детализации классической триады, актуализируется вопрос относительно ее достаточности в современных условиях. Также безусловный интерес вызывает нахождение особенностей и/или общего вектора формирования системы составляющих устойчивого развития предприятий, исходя из вида их экономической деятельности, размера.

Предприятие относится к сложной, открытой социально-экономической системе, характеризующейся традиционным набором проявлений системности, т.е. элементами и связями между ними, функциями и, конечно, эмерджентным эффектом. Предпринимательская структура с этих позиций рассматривается через форму организации данных элементов и установления связей между ними, которая соответствует выполнению заданных функций и способствует обеспечению целей деятельности. Структурные элементы предприятия характеризуются многообразием, в их число входят отдельные подразделения, цеха, группы работников и многое другое. Взаимосвязь структурных элементов предприятия по определенным классификационным признакам обеспечивает формирование его соответствующих подсистем. Между подсистемами и элементами предпринимательской структуры осуществляется целый набор сложных связей, среди которых ключевыми являются материальные, экономические, финансовые, социальные, энергетические, информационные. Изменения в состоянии подсистем предприятия являются непрерывными, порой циклическими в соответствии с закономерностями их развития и внешними условиями. Очевидно, что их устойчивость является определяющей на пути обеспечения устойчивого развития предприятия.

Сущностные и структурные характеристики предпринимательства обусловливают абсолютную логичность и правомерность выделения различных составляющих по подсистемам предприятия в контексте его устойчивого развития. При этом данные компоненты могут обозначаться в качестве видов устойчивости или сфер деятельности без подобного обозначения, обозначаться явно или косвенно, указываться в самом определении или проявляться в дальнейшем обосновании, при формировании среза для оценки и пр.

Так, Гусев И.С. в число составляющих устой- 
чивого развития предприятия включает экономическую, социальную, экологическую и рисковую устойчивости [4, с. 236-254]. Аксенов П. В. выделяет аналогичные виды, однако, экономическую устойчивость представляет в свою очередь финансовой, организационной, маркетинговой, инвестиционной, производственной, технико-технологической устойчивостью, а также социальную, экологическую и рисковую устойчивость [1]. КондауроваД.С. при схожести точки зрения не осуществляет дальнейшего подразделения экономической устойчивости, а выделяет в общем финансовую, маркетинговую, технологическую, организационную, инвестиционную устойчивости [7]. Несколько меньшее число компонентов устойчивого развития соответствует подходу Пелымской О.В.- экономическая, финансовая, производственная, кадровая, инвестиционная устойчивости [10, с. 132]. Рассветов С.А. считает целесообразным группировку финансовой и экономической устойчивости, а также производственной и технологической в объединенные виды, но при отдельном выделении социальной устойчивости [11, с.97-98].

Зингер О.А. помимо широко распространенных финансовой и производственной также прибегает к рыночной и инновационной устойчивостям [5, с. 182]. Батырова Н. С. полагает, что устойчивое развитие определяется экономической, технологической, экологической, организационной составляющей и социальной устойчивостью [3, с.16, 18]. Сидоров В.М., также придерживаясь точки зрения о выделении именно видов устойчивости, к их числу относит экономическую, социальную, технологическую, экологическую и отдельно от кадровой, социальной или организационной - управленческую устойчивость [12, с. 59].

Калюжный В.Ю. предпринял попытку объединения большей части подходов, выделив маркетинговую, производственную, финансовоэкономическую, инновационную, инвестиционную, кадровую устойчивости [6]. Кучерова Е.Н. еще в большей степени постаралась объединить виды устойчивости в контексте устойчивого развития, добавив к экономической, производственной, маркетинговой, социальноэкономической, финансовой управленческую и экологические устойчивость [8, с. 78].

Отличительной особенностью подхода Лазарева И.Н. является обозначение в качестве составляющих устойчивого развития, помимо традиционных производственно-технической и финансовой устойчивостей, также устойчивость сырьевого обеспечения [9, с. 500].

Отметим, что некоторые авторы, все же используют традиционную триаду - экономическая, социальная, экологическая устойчивости без подразделения или выделения прочих видов. Другие авторы добавляют четвертый компонент, но также без последующего подразделения - например, стратегическую устойчивость, технологическую, институциональную, правовую, производственную, инновационную компоненты. Другие или отдельно от экономической выделяют финансовую составляющую или заменяют одну другой.

Вышеприведенные примеры отражают ключевые подходы к структурной характеристике устойчивого развития предприятий. Основываясь на базе теоретических исследований, в т.ч. включая те авторские подходы, в которых отсутствует прямое указание на виды составляющих, осуществлена систематизация структурной характеристики устойчивого развития (табл. 1). Группа 1 - наибольшая частота использования, группа 2 - средняя частота, группа 3 - низкая частота, группа 4 - единичное использование.

В качестве ключевого общего вектора по предприятиям всех размеров и видов деятельности необходимо отметить финансовоэкономическую и социально-кадровую компоненты как наиболее частые используемые для характеристики устойчивого развития.

Кроме того, в этой же группе, но в рамках предприятий сферы услуг и АПК всех размеров находится экологическая составляющая. Со средней частотой для крупных предприятий всех видов деятельности выделялась производственнотехнологическая компонента, для средних и малых предприятий в данной группе общей являлась эта же компонента, но только для сферы услуг и строительства. Рыночная компонента являлась общей в средней группе для предприятий сферы слуг и промышленности всех размеров. Редкая частота выделения экологической составляющей характерна для средних и малых промышленных и строительных предприятий. В единичных случаях при структурном рассмотрении устойчивого развития промышленных и сельскохозяйственных предприятий всех размеров используется инвестиционная компонента.

По итогам проведенного анализа можно утверждать, что характеристика устойчивого 
Таблица 1. Результаты компонентного анализа устойчивого развития предприятий

\begin{tabular}{|c|c|c|c|c|c|}
\hline & & & Гру & 2a 1 & \\
\hline & & $\begin{array}{c}\text { финансово- } \\
\text { экономическая; } \\
\text { социально- } \\
\text { кадровая }\end{array}$ & $\begin{array}{c}\text { финансово- } \\
\text { экономическая; } \\
\text { социально- } \\
\text { кадровая; } \\
\text { экологическая }\end{array}$ & $\begin{array}{c}\text { финансово- } \\
\text { экономическая; } \\
\text { социально- } \\
\text { кадровая }\end{array}$ & $\begin{array}{c}\text { финансово- } \\
\text { экономическая; } \\
\text { социально- } \\
\text { кадровая; } \\
\text { экологическая }\end{array}$ \\
\hline & & & Гру & za 2 & \\
\hline & & $\begin{array}{c}\text { рыночная; } \\
\text { производственно- } \\
\text { технологическая; } \\
\text { экологическая }\end{array}$ & $\begin{array}{c}\text { производственно- } \\
\text { технологическая }\end{array}$ & $\begin{array}{c}\text { производственно- } \\
\text { технологическая }\end{array}$ & $\begin{array}{c}\text { производственно- } \\
\text { технологическая; } \\
\text { рыночная }\end{array}$ \\
\hline & Крупные & & Гру & na 3 & \\
\hline & & $\begin{array}{c}\text { управленческая; } \\
\text { ресурсная; } \\
\text { инновационная }\end{array}$ & $\begin{array}{c}\text { рыночная (марке- } \\
\text { тинговая, деловая } \\
\text { активность) }\end{array}$ & $\begin{array}{l}\text { инвестиционная; } \\
\text { экологическая }\end{array}$ & - \\
\hline & & & Гру & la 4 & \\
\hline$\stackrel{\theta}{\theta}$ & & $\begin{array}{c}\text { инвестиционная; } \\
\text { рисковая; } \\
\text { интеллектуальная; } \\
\text { правовая; } \\
\text { институциональ- } \\
\text { ная; } \\
\text { логистическая; } \\
\text { стратегическая }\end{array}$ & $\begin{array}{c}\text { организационная; } \\
\text { инвестиционная }\end{array}$ & - & - \\
\hline ఝ్ల & & & Гру & na 1 & \\
\hline & & $\begin{array}{c}\text { финансово- } \\
\text { экономическая; } \\
\text { производственно- } \\
\text { технологическая; } \\
\text { социально- } \\
\text { кадровая }\end{array}$ & $\begin{array}{c}\text { финансово- } \\
\text { экономическая; } \\
\text { социально- } \\
\text { кадровая; } \\
\text { экологическая }\end{array}$ & $\begin{array}{c}\text { финансово- } \\
\text { экономическая; } \\
\text { социально- } \\
\text { кадровая }\end{array}$ & $\begin{array}{c}\text { финансово- } \\
\text { экономическая; } \\
\text { социально- } \\
\text { кадровая; } \\
\text { экологическая }\end{array}$ \\
\hline & & & Гру & เa 2 & \\
\hline & & рыночная & - & $\begin{array}{c}\text { производственно- } \\
\text { технологическая }\end{array}$ & $\begin{array}{c}\text { производственно- } \\
\text { технологическая; } \\
\text { рыночная }\end{array}$ \\
\hline & ЧреднИЕ И Мाалые & & Гру & na 3 & \\
\hline & & $\begin{array}{c}\text { организационная; } \\
\text { управленческая; } \\
\text { экологическая; } \\
\text { инновационная; } \\
\text { ресурсная }\end{array}$ & $\begin{array}{c}\text { рыночная; } \\
\text { производственно- } \\
\text { технологическая }\end{array}$ & экологическая & - \\
\hline & & & Гру & 2a 4 & \\
\hline & & $\begin{array}{c}\text { инвестиционная; } \\
\text { интеллектуальная; } \\
\text { логистическая; } \\
\text { стратегическая }\end{array}$ & инвестиционная & рыночная & - \\
\hline & & Промышленность & АПК & Строительство & Сфера услуг \\
\hline & & & Вид дея & ЛЬНОсти & \\
\hline
\end{tabular}


развития предприятий производится по типичному набору составляющих, отличие заключается только в частоте использования некоторых из них в зависимости от размера и сферы предпринимательской деятельности. Осталась не охваченной по предприятиям всех сфер деятельности и размеров информационная составляющая, которая должна отражать информационные связи, выполняющие обеспечивающую и объединяющую функцию. Безусловно, информация, информационная связанность внутри предприятия, уровень информационной коммуникации с потребителями, поставщиками и пр. контрагентами может рассматриваться как внутренний фактор устойчивого развития. Однако современные условия предпринимательской деятельности, особенно в период пандемии COVID-19, показали, что цифровизация должна являться характерной чертой предприятия, ориентированного на выживание в любых условиях. В этой связи информационная подсистема представляет теперь не просто «вход-выход» данных с определенным качеством обработки, что может рассматриваться как сильные или слабые стороны предприятия, а подсистему цифровизации, устойчивость которой является детерминантой устойчивого развития.

Это связано с тем фактом, что информационная система как подсистема предприятия включает в себя не только данные и знания, т.е. информацию, но также и информационные технологии. Информационные системы бывают различных видов - вербальные, документарные, автоматизированные. Именно последние, а также полностью автоматические являются непременным условием устойчивого развития современного предприятия, позволяя не только качественно и своевременно обрабатывать информацию любого объема и уровня сложности, но и обеспечивать устойчивые информационные связи между различными субъектами как во внутренней, так и во внешней среде предприятия. Таким образом, устойчивость информационной подсистемы или по-другому информационная устойчивость, во-первых, является отражением класса автоматизации процесса получения, хранения, преобразования, передачи информации, во-вторых, отражением наличия и качества коммуникационных каналов предприятия, в-третьих, отражением безопасности, надежности и бесперебойности компьютерной сети предприятия.

Таким образом, для структурной характеристики устойчивого развития предприятия традиционную триаду «экономика-социумэкология» предлагается преобразовать в тетраду «экономика-социум-экология-информация». Другими словами, формируют устойчивое развитие предприятия экономическая, социальная, экологическая, информационная устойчивость. выделение прочих видов устойчивости, которые в свою очередь формируют экономическую составляющую устойчивого развития, «утяжеляет» его структурную характеристику. В детализированном разрезе экономическая устойчивость характеризуется через финансовую (включая инвестиционные аспекты), рыночную, производственную и пр. виды устойчивостей.

\section{Библиографический список}

1. Аксенов П.В. Обеспечение устойчивого развития промышленного предприятия на основе стратегических конкурентных преимуществ: дис. ... канд. экон. наук: 08.00.05 / Аксенов Павел Вячеславович.- М.: Финансовый университет при Правительстве Российской Федерации, 2016. - 214 с.

2. АрошидзеА.А. Теория и методология управления экономической составляющей устойчивого развития предпринимательских структур: монография.- Новосибирск: Изд. ООО «СибАК», 2019. - 194 с.

3. БатыроваН.С. Методологические основы разработки и реализации стратегии устойчивого развития хозяйствующего субъекта / Н.С.Батырова // Экономический анализ: теория и практика.- 2014.- № 44 (395). - С.14-25.

4. Гусев И.С. Научно-методическое обеспечение многоцелевого управления устойчивым развитием промышленного предприятия / В кн.: Формирование новой экономики и кластерные инициативы: теория и практика: монография / И.С. Гусев.-СПб.: Санкт-Петербургский политехнический университет Петра Великого, 2016. с. 236-254.

5. Зингер О.А. Исследование подходов к определению устойчивого развития промышленного предприятия / О.А.Зингер // Современные проблемы науки и образования: электронный научный журнал. - 2014.№ 6.- URL: https://science-education.ru/ru/article/view?id=16459 (дата обращения 28.02.2021). 
6. Калюжный В.Ю. Формирование стратегии устойчивого развития предприятия в условиях освоения инноваций: автореф. дис. ... канд. экон. наук: 08.00.05 / Калюжный Владислав Юрьевич.- Воронеж: Воронежская государственная технологическая академия, 2009.-26 с.

7. КондауроваД. С. Разработка рекомендаций по развитию механизма управления устойчивым развитием промышленных предприятий / Д. С. Кондаурова // Управление экономическими системами: электронный научный журнал. - 2015. - № 9 (81)._ URL: http://uecs.ru/uecs-81-812015/item/3707-2015-09-21-06-33-51 (дата обращения 28.02.2021).

8. Кучерова Е. Н. Современный подход к устойчивому развитию предприятия / Е. Н. Кучерова // Вестник Оренбургского государственного университета (ОГУ). - 2007. - № 9.- С.76-81.

9. Лазарев И.Н. Механизмы обеспечения устойчивого развития мясоперерабатывающих предприятий / И.Н. Лазарев, Ю.В. Журавлев, И. М.Подмолодина // Экономика и предпринимательство.-2014.- № 4-2 (45). - С.500- C.507.

10. Матыс Е.Г., Пелымская О.В. Оценка устойчивости строительного предприятия на разных стадиях его жизненного цикла / Е. Г. Матыс, О.В.Пелымская // Успехи современной науки и образования. - 2016. - Т. 3 № $11 .-$ C. $132-136$.

11. Рассветов С.А. Направления устойчивого развития промышленных предприятий / С.А. Рассветов // Вестник Тамбовского университета. - 2012. - № 8 (112). - С.96-99.

12. Сидоров В. М. Оценка устойчивого развития предприятия с помощью организационно-экономического механизма / В. М. Сидоров // Вопросы региональной экономики. -2013. - № 1 (14). - С.59-62. 